\title{
Digital Marking in Prosthodontics
}

\author{
Arjita Dutta ${ }^{1}$, Prakash Nidawani², Harsha R.H. ${ }^{3, *}$, Girish Galagali ${ }^{4}$, Sidharth S P ${ }^{5}$ \\ ${ }^{1}$ Post Graduate, ${ }^{2,3}$ Professor, ${ }^{4}$ Professor\& HOD, ${ }^{5}$ Associate Professor ${ }^{1-4}$ Navodaya Dental College, ${ }^{5}$ KIMS Dental College
}

*Corresponding Author:

Email: adutta544@gmail.com

\begin{abstract}
Forensic science helps us with examination of accidents or crime scene and also gather information related to medicolegal cases. Prosthodontist plays a major role in forensic odontology and highly significant after the invention of denture labeling techniques. Identification of a person gets very difficult in case of accident, loss of memory state of unconsciousness and in hospitals. Labeled denture helps us to identify the dead after disasters, in emergency situation and accidents. There are various types of marking system used these days and also described in literature. This case report highlights a technique of denture identification wherein a quick response code (QR Code) is incorporated into the processed denture using a clear acrylic.
\end{abstract}

Keywords: Denture, QR Code, Forensic, Acrylic.

\section{Introduction}

Forensics was born when the body of Charles the Bold was identified in the battle of Nancy by the absence of a tooth in the lower arch. Later in 1835 the importance of prosthesis in forensics came into the picture when a burned body was identified by the gold denture of the victim. ${ }^{1}$ After World War II, out of 3,000 bodies of unidentified soldiers $27.3 \%$ of the bodies were found to have dental prostheses but only $0.3 \%$ of these could be identified. ${ }^{2,3}$ Forensic Odontology is one of the branch in dentistry which handles and examine dental evidences and evaluate and present dental findings in case of medicolegal cases in our judicial system. ${ }^{4} \mathrm{~A}$ very important role is played by the prosthodontist in forensic dentistry as they fabricate various prostheses which helps as an important tool for identification after the invention of denture labeling techniques. ${ }^{5}$ Personal identification is inevitable in case of major disasters and accidents like

Earthquakes, fire, plane crashes, loss of memory state of unconsciousness and in hospitals. ${ }^{6}$ Identification of the dead gets easier with denture identification system. Positive identification is an essential requirement for any medicolegal investigation in forensics ${ }^{7,8}$ older age group is the population segment that is statistically associated to usage of complete denture. This fact suggests that many of these patients show diminished cognitive and motor functions, memory loss or dementiva. Also many of them leave in old age institutions. Additionally there must be a high incidence of health problems that may require hospitalizations. It is common under these circumstances to expect loss of removable prostheses or confusion regarding who they belong to.

For this reason the placement identification elements within the dentures will simplify the caretakers' work and notably reduce the risk of denture loss for the patients.
Thus labeling dentures are totally necessary. ${ }^{9}$ most international dental associations and forensic odontologists have recommended and made it mandatory to label all the dentures. The labeling of dentures is regulated by legislation, in some countries and certain states of the USA. ${ }^{10}$ The recommendations issued by Sweden the National Board of Health and Welfare states that "the patient shall always be offered denture marking and be informed about the benefit there of denture marking depends totally on patient's choice and is not permitted if the patient refuses to get it done". The American Dental Association have specified certain criteria for denture marking. ${ }^{11}$

1. The identification should be specific

2. The technique should be simple

3. The mark should be fire and solvent resistant

4. The denture should not be weakened

5. The mark should be cosmetically acceptable

The recommended areas for marking therefore are the posterior regions of the lingual flange in the mandible and the palate of the maxillary denture. ${ }^{12}$ Denture marking can be broadly classified under two headings, they are Surface Method and Inclusion Method. The Surface method, to engrave any letter or identification mark on the denture.

Surface often referred to as scribing technique and in the embossing technique, the master cast is scratched with any identification mark or patient's details and a embossed letter is imprinted on the impression surface of dentures. This technique is cost efficient but leads to food entrapment, infection and irritation. In inclusion method, the markings are entrapped within the patient's denture.

The various denture markers include quick response code (QR Code) denture barcoding, lenticular card, ID band, paper strip $\mathrm{T}$ bar, laser etching, electronic microchips, photographic, radiofrequency identification (RFID) tags and subscriber identity module (SIM)..$^{1-3,13}$ Regardless of the method used to identify a person, the 
results of the comparison of antemortem and postmortem data lead to 1 of these 4 situations: 14

1. Positive identification: There is not much difference observed as the items to be compared are totally different in the antemortem and postmortem databases.

2. Possible identification: Commonalities exist among the comparable items in the antemortem and postmortem databases but enough information is missing from either source to prevent the establishment of a positive identification.

3. Insufficient identification evidence: This is an inconclusive identification as sufficient supportive evidence is not available for comparing and definitive identification, but we cannot rule out the suspected identity of the decedent.

4. Exclusion: difficult to tally as there is a huge discrepancy between the comparable items in the antemortem and postmortem databases. Denture labeling can be a boon to many and is of great significance. It is important to gain more knowledge on the reliability of denture markers. This study and case report relates to $\mathrm{QR}$ Code.

Inclusion and it is one of the best technique because of its simplicity and accuracy. According to the survey "The number of population using smart phone in India is estimated to reach 299.24 million, with the number of smart phone users worldwide forecast to exceed 2.3 billion users by that time in 2017 . The number of smart phone users worldwide is projected to amount to nearly 2.7 billion by 2019." Fig. 1 and Fig. 2 QR codes are very common in daily life and most people are exposed to them in the media on a daily basis. QR code stands for Quick Response code and is a two dimensional barcode created in Japan in 1994 for the automotive industry. It is formed by black squares arranged on a square grid. It has a white background and can easily be optically read with an imaging device such as the camera of a smart phone that has the appropriate program installed. It can hold large amounts of information, up to 4,296 alphanumeric characters. ${ }^{15}$ this characteristic and the fact that it is easily generated and read makes it ideal to use in denture labeling.

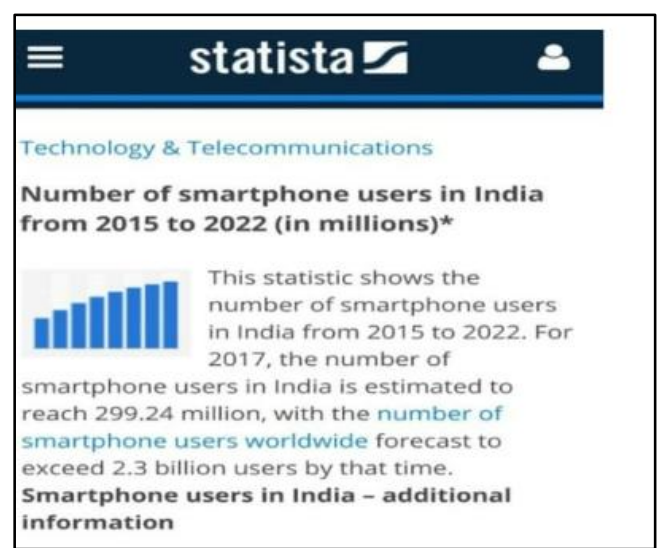

Fig. 1: Smart phone years in the year 2017

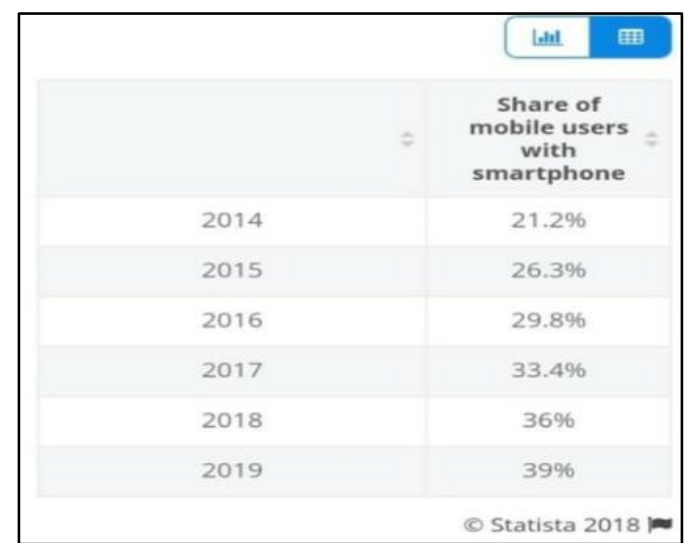

Fig. 2: Average Percentage of smart phone users from the year 2014-2019

\section{Methodology and Technique}

Technique: The aim of the study is to validate the efficacy of QR code incorporation in removable prosthesis. This study is done to help in post mortem, to identify victims in natural calamities or accidents, in medicolegal cases, in geriatric institutions.

The material used - QR Code, QR Code Scanner, Lamination, Denture, Clear Acrylic Resin Fig. 3.

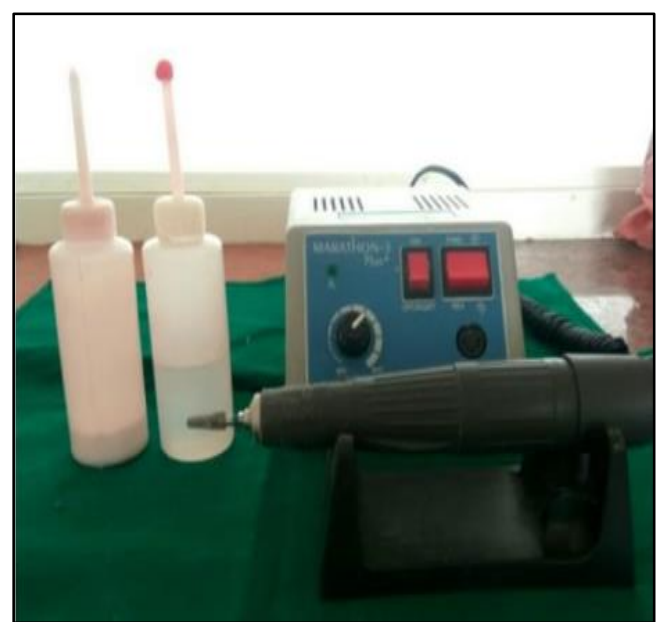

Fig.3: Clear Acrylic, Junction Box 


\section{Methodology: QR Code Labeling Technique}

Barcode: A barcode is an optical machine-readable code in the form of patterns which is a representation of data barcode scanner is used to read this kind of patterns. Barcodes is a better incorporation. Technique as it stores a huge amount of patient's details as compared to labels which just includes name and ID number. Quick response code is a two dimensional (2D) type of barcode ${ }^{16,17}$ Fig. 4.

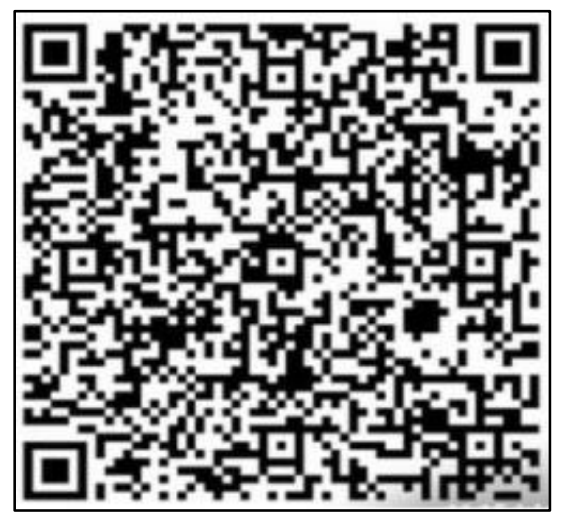

Fig. 4: QR Code is generated

Barcode Scanner: The barcode (QR Code) are often simply scanned and also the patient knowledge are disclosed straight off at intervals seconds.

The barcode scanner application is easily downloaded from the web and installed in an android device or any smart phone. 18,19There are several QR generator applications on the internet. Most of them are free of charge since QR Code technology is freely licensed if the standards are followed. Information placed in the code should include at least these general data's.

Name of the patient

Identification number

Age/Sex

Address /Telephone number

Occupation

Dentist's name and contact

Any relevant health information \& Blood Group

With this information a QR code is generated and printed on a butter paper and well protected by lamination. Fig. 6 the size of the square for a maxillary denture should have a maximum of $22 \mathrm{~mm}$ per side and it must be adjusted to the proper size of the denture. For a mandibular denture, the possibility of using a readable QR code depends on the size of the flange at the buccal shelf area. A minimum size of $17 \mathrm{~mm}$ per side is necessary. Fig. 5. These dimensions are necessary because a very large code would be bent as the intaglio of the denture is convex and reading would be compromised. If the code is too small it will be difficult to scan it. A slot is created on the preferable location. The QR Code is placed in the slot and auto polymerizing clear acrylic resin is placed over the barcode till the surface level of denture. Fig. 7.

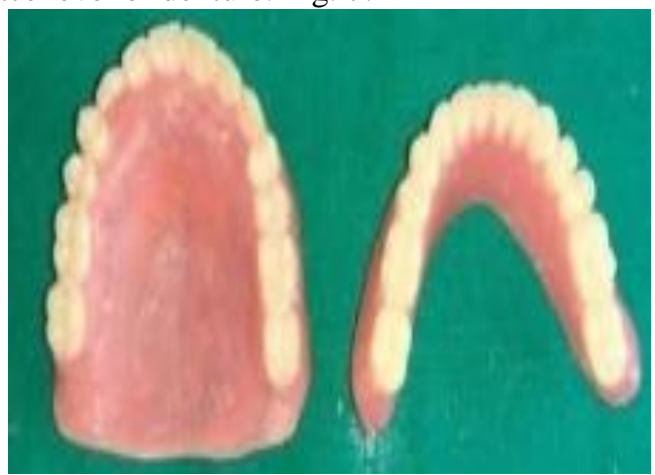

Fig. 5: Grooves are created on the maxillary Prosthesis

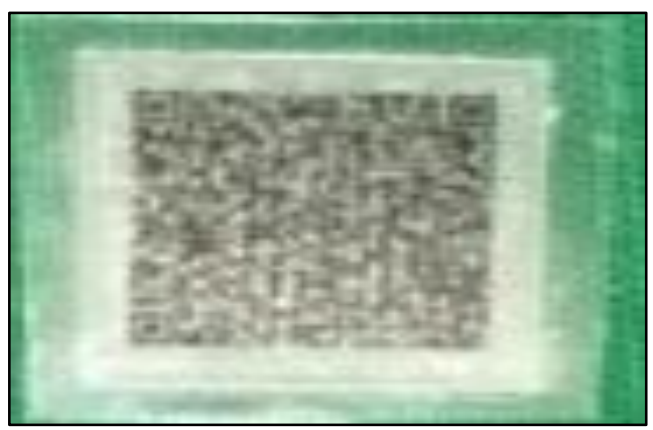

Fig.6: Laminated using clear acrylic resin

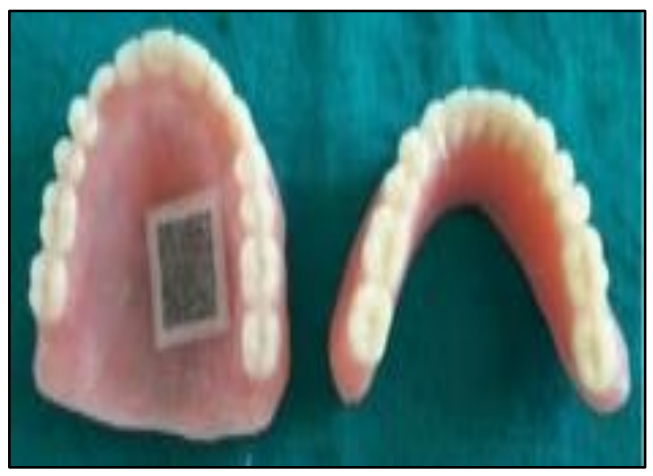

Fig. 7: QR Code is placed

\section{Case Report}

An old female patient of age 52 years visited to our hospital (Navodaya Dental College and Hospital, Raichur, Karnataka, India) with a chief complaint of missing teeth and difficulty in eating. There was no relevant medical history. After intraoral examination it was revealed the patient was completely edentulous with respect to her the maxillary and mandibular arches. The main purpose was to deliver a 'labeled' removable prosthesis to the patient which as well as restore the form, function and esthetics of the oral cavity.

1. Firstly the patient and patient's family was educated and motivated about the beneficial use and importance of denture marking system.After the 
patient's approval a Consent form was given to the patient and patient's signature is taken for documentation for later use. Fig. 8.

2. A primary impression of maxilla and mandible was made with impression compound.

3. The cast was poured and the denture is fabricated by following the regular clinical and lab steps.

4. QR Code is made using the patient's details from the case history.

5. A groove of $1.5 \mathrm{~mm}$ depth is created in accordance with the QR Code size on the palate/lingualflange of the denture without affecting its structure.

6. With the help of auto polymerizing clear acrylic resin the QR Code is fixed onto the groove which is being created.

7. Auto polymerizing acrylic resin is used to fuse the margins as well to the denture.

8. The finishing and polishing of the denture is done in the usual manner.

9. After the insertion the denture is inspected for comfort, retention, esthetics and function in the patient's mouth.

10. With the help of a inbuilt scanner in our regular smart phone the QR Code was deciphered in seconds.

11. The result obtained of the decoded QR Code was in a plain text format. Fig.9,10,11,12.

\section{Advantages}

1. No seepage of monomer into the QR Code

2. Simple to construct

3. No distortion or air voids over the QR Code

4. Inexpensive

5. Does not alter the structure, adaptation and esthetics of the denture

6. Gives definite information.

7. Cost Effective

8. Easy to handle

9. Cannot be duplicated

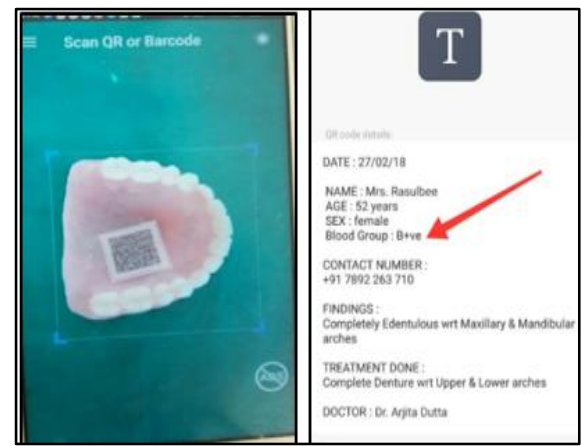

Fig. 9 \& 10: scanning the QR Code using smart phone deciphered \& quick response QR Code

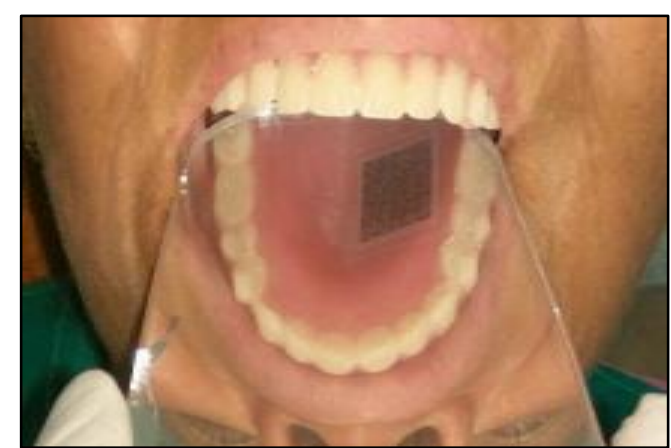

Fig. 11: QR code scanned details

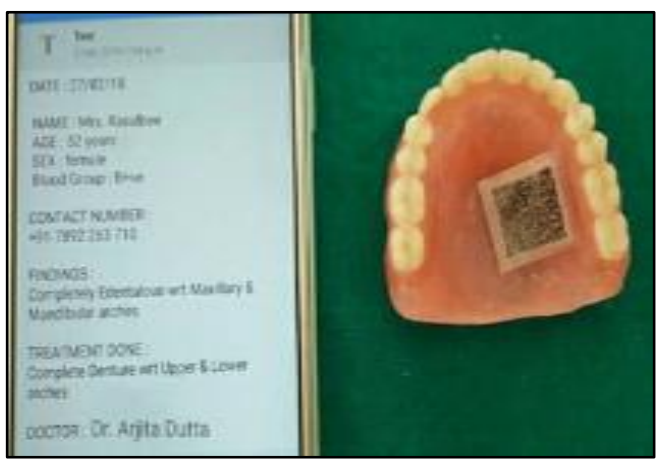

Fig. 12: QR Code places on patient's denture

\section{Conclusion}

Quick response code labeling is a good methodology in dental plate identification systemand. We are restoring all our patient details from our department for future use in our personal website in this case. The patient was satisfied with the removable denture in terms of comfort, function and esthetics. The laminated QR Code was not damaged by saliva or denture cleansing solution. It is the role of a dentist to motivate patients toward denture identification system. A QR Code is chosen as one of the mode of denture marking system because of its simplicity accuracy cost and as it can store a huge amount of data and doesn't need a separate scanner to scan it and can also be implemented in removable orthodontic retainers, removable prosthesis and crowns and.

Its most unique easy to handle, feasible, cannot be duplicated can be used as a reference to other dentist for future treatment plan and also as a storing data for patient information in colleges, institutions and academic purposes. It can also add to help in old age homes to identify between many dentures and also for identification of a person and as a forensic evidence to identify the dead and can act as a lifesaving medium in accidents and emergency if the blood group of the victim is been mentioned. But it has to be made mandatory for all the institutions and dental clinic to incorporate denture identification system in there prostheses and people has to be made aware to check for the prostheses for emergency situation like road traffic accidents and the required bloodgroup can be arranged and by this, this will be a noble lifesaving option. 


\section{References}

1. Ling BC. Computer-printer denture microlabeling system. J Prosthet Dent. 1998;79:363-64.

2. Avon SL. Forensic odontology: The roles and responsibilities of the dentist. J can Dent Assoc

3. 2004;70:453-58.

4. Gosavi S, Gosavi S. Forensic odontology: A prosthodontic view. J Forensic Dent Sci. 2012;4:38-41.

5. Dr. Rathee M, Dr. Yadav K . Denture Identification Methods.J of Dent and Medical Sciences. 2015 ;58-61

6. Mohan J, Kumar DC, Simon P. "Denture Marking" as an Aid to Forensic Identification. J Indian Prosthodont Soc. 2012;12(3):131-36.

7. Jain AR, et al. A New Alternative Technique for Denture Identification. World J of Dent. 2015;6(3):188-92.

8. MacEntee MI, Campbell T. Personal identification using dental prostheses. J Prosthet Dent. 1979;41:377-80.

9. Richmond R, Pretty IA. Denture marking - Patient preference of various methods. J Forensic Sci. 2007;52:1338-42.

10. Rodrigo A. Denture Labeling Using QR Codes. A Simplified Technique. Int J of Dental Sci. 2017;33:16591046.

11. Poovannan et al.: The reliability of QR code denture. $J$ Forensic Dent Sci. 2016;8:179.

12. Clark DH, Cainio P (eds) y. Butterworth-Heinemann, Boston; Practical forensic dent. 1992.

13. Ryan LD, Keller JB, Rogers DE, Schaeffer L. Clear acrylic resin T-bar used in denture identification. JProsthet Dent. 1993;70:189-90.

14. Berry FA, Logan GI, Plata R, Riegel R. A postfabrication technique for identification of prosthetic devices.J Prosthet Dent. 1995;73:341-43.

15. Guidelines for bite mark analysis. American Board of Forensic Odontology. IncJ Am Dent Assoc. 1986;112(3):383-86.

16. Informationcapacity and versions of QR Code. 2017. Retrieved fromhttp://www.qrcode.com/en/about/verion.html

17. Stevenson RB. Marking dentures for identification. $J$ Prosthet Dent. 1987;58:255.

18. Ryan LD, Keller JB, Rogers DE, Schaeffer L. Clear acrylic resin T-bar used in denture identification. $\mathrm{J}$ Prosthet Dent. 1993;70:189-190.

19. Reeson MG. A simple and inexpensive inclusion technique for denture identification. $J$ Prosthet Dent. 2001;86:441-42.

20. Matsumura H, Shimoe S. Incorporation of a cast, embossed identification plate into a partial denture framework. J Prosthet Dent. 2002;88:215-217.

How to cite the article: Dutta A, N. Prakash, Harsha R. H, Galagali G, Sidharth S. P. Digital Marking in Prosthodontics. Ann Prosthodont Restor Dent 2018;4(4):122-126 